\title{
VASOPRESSIN SERUM LEVELS AND DISORDERS OF SODIUM AND WATER BALANCE IN PATIENTS WITH SEVERE BRAIN INJURY
}

\author{
Eliane de Araújo Cintra', Sebastião Araújo², \\ Elizabeth M.A.B. Quagliato ${ }^{3}$, Margaret de Castro4, \\ Antônio Luiz Eiras Falcão², Desanka Dragosavac', Renato G.G. Terzi5
}

\begin{abstract}
Background: Disorders of water and sodium balance are frequently seen in patients with severe brain injury (SBI), and may worsen their prognosis. Purpose: To evaluate vasopressin (AVP) serum levels and sodium and water balance disorders during the first week post-injury in patients with SBI. Method: Thirty-six adult patients with SBI (admission Glasgow Coma Scale score $\leq 8$ ) and an estimated time of injury $\leq 72$ hours were prospectively studied. Clinical and laboratory data were recorded and AVP was measured in venous blood samples collected on the $1^{\text {st }}, 2^{\text {nd }}, 3^{\text {rd }}$ and $5^{\text {th }}$ days following inclusion. Results: AVP serum levels remained within the normal range in SBI patients (either traumatic or non-traumatic), although tended to be greater in non-survivor than in survivor patients ( $p=0.025$ at $3^{\text {rd }}$ day). In-hospital mortality was $43 \%$ $(15 / 36)$, and serum sodium and plasma osmolality variabilities were greater in non-survivor than in survivor patients during the observation period $(p<0.001)$. Conclusion: AVP serum levels remained within the normal range values in these SBI patients, but those who died have shown higher incidence of abnormal sodium and water balance during the first week post-injury.
\end{abstract}

KEY WORDS: vasopressin, severe brain injury, hyponatremia, hypernatremia.

\begin{abstract}
Níveis séricos de vasopressina e distúrbios de sódio e água em pacientes com lesão cerebral grave
RESUMO - Antecedentes: Desordens do balanço de água e sódio são frequentemente vistas em pacientes com lesão cerebral grave (LCG), podendo agravar o prognóstico. Objetivo: Avaliar os níveis séricos de vasopressina (AVP) e a incidência de distúrbios da água e sódio na primeira semana pós-lesão em pacientes com LCG. Método: Trinta e seis pacientes adultos com LCG (pontuação inicial na escala de coma de Glasgow $\leq 8$ ) e tempo estimado de lesão $\leq 72 \mathrm{~h}$ foram estudados prospectivamente. Dados laboratoriais e clínicos foram registrados e os níveis séricos de AVP foram mensurados no $1^{\circ}, 2^{\circ}, 3^{\circ}$ e $5^{\circ}$ dias pós-inclusão. Resultados: A AVP manteve-se dentro da faixa de normalidade nestes pacientes, mas mostrando-se proporcionalmente mais elevada nos pacientes que não sobreviveram ( $p=0,025$ no $3^{\circ}$ dia). A mortalidade intra-hospitalar foi $43 \%$ (15/36) e as variações do sódio e osmolalidade plasmáticos foram maiores nos pacientes que não sobreviveram durante o período de observação $(p<0,001)$. Conclusão: Os níveis séricos de AVP mantiveram-se dentro da faixa de normalidade nestes pacientes com LCG, mas aqueles não sobreviventes mostraram maior incidência de anormalidades do balanço de água e sódio durante a primeira semana de evolução.
\end{abstract}

PALAVRAS-CHAVE: vasopressina; lesão cerebral grave; hiponatremia; hipernatremia.

Patients with severe brain injury (SBI), such as traumatic brain injury (TBI), hemorrhagic stroke (HS), ischemic stroke (IS) and subarachnoid hemorrhage (SAH) frequently have abnormal arginine-vasopressin (AVP) secretion. The patho-physiological mechanisms of AVP secretion have not yet been clearly defined'. Various investigators have measured AVP in plasma and in cerebrospinal fluid (CSF) in patients with SBI and reported high levels, suggesting that increased AVP secretion may contribute to increase the primary lesion severity $^{2,3}$. Other investigators have suggested that AVP serum levels may affect the mechanisms of cardiovascular regulation of cerebral edema ${ }^{4}$. In a previous study ${ }^{5}$, we compared AVP serum levels of healthy

Department of Neurology, Faculty of Medical Sciences (FCM), State University of Campinas, Campinas SP, Brazil (UNICAMP); Department of Surgery, FCM-UNICAMP; Department of Clinical Medicine, Faculty of Medicine, Ribeirão Preto, University of São Paulo, Ribeirão Preto SP, Brazil (FMRP-USP) and Intensive Care Unit, Hospital de Clínicas, UNICAMP: 'Doctoral Student, Department of Neurology, UNICAMP; ${ }^{2}$ PhD, Assistant Professor, Department of Surgery, UNICAMP; ${ }^{3} \mathrm{PhD}$, Assistant Professor, Department of Neurology, UNICAMP; ${ }^{\mathrm{PhD}}$, Associated Professor, Department of Internal Medicine, FMRP-USP; ${ }^{5}$ PhD, Full Professor, Department of Surgery, UNICAMP.

Received 1 October 2006, received in final form 3 August 2007. Accepted 3 September 2007.

Dra. Eliane de Araújo Cintra - Rua Comendador Querubim Uriel 186 / 23 - 13024-470 Campinas SP - Brasil. E-mail: cintra@hc.unicamp.br 
individuals with those of patients with SBI or brain death, and found a great variation in AVP values in the group with $S B I$, but no significant differences in mean plasma AVP levels between the three groups. A negative correlation between plasma osmolality and sodium was also found, suggesting the presence of syndrome of inappropriate antidiuretic hormone secretion (SIADH) in SBI group. Disorders of the sodium/water balance, particularly diabetes insipidus (DI) and SIADH, are common complications reported in the acute phase of SBI, either traumatic brain injury or stroke, and contribute to the high morbidity and mortality observed in these patients ${ }^{6,7}$. Moderate and occasionally severe hyponatremia has been reported in around $30 \%$ of neurosurgical patients with SAH. The decrease in serum sodium was progressive, leading to neurological problems, such as confusion, lethargy, convulsions and, finally, coma ${ }^{8}$.

Hyponatremia was first reported in 1950 in patients with SBI. Excessive natriuresis was observed and the term "cerebral salt-wasting syndrome" was coined $^{9}$. The hypothesis of the natriuretic factor was not raised and, following the discovery of the antidiuretic hormone, SIADH was mentioned as the causal mechanism of hyponatremia in patients with $\mathrm{SBI}{ }^{10}$. The pathophysiology of the secretion and liberation of AVP and the mechanisms involved in sodium and water disorders in patients with acute severe brain lesion have not been adequately clarified. In many studies increased levels of AVP have been found and it has been suggested that this increase, in the early stages of the injury, may be of significant importance in the pathogenesis of cerebral edema ${ }^{11}$.

Therefore, the objective of the present study was to evaluate plasma AVP levels and the incidence of sodium and water disorders during the first week postinjury in acute severe brain injured patients.

\section{METHOD}

The present study was carried out in the adult intensive care unit of the Hospital de Clínicas, State University of Campinas, between January 2003 and March 2005. The study protocol was approved by the Institutional Research Ethics Committee (Protocol N $\mathrm{N}^{\mathrm{er}}$ : 211/2002), and in all cases a written informed consent was obtained from a surrogate prior to enrollment.

Study population - Severe brain injured group was composed of 36 patients, both sexes, aging $\geq 18$ years, with initial Glasgow Coma Scale (GCS) score $\leq 8$, and an estimated time of injury $\leq 72$ hours, enrolled non-consecutively. Exclusion criteria were: aging $<18$ years; associated major thoracic or abdominal trauma; sepsis; irresponsive circulatory shock; patients pregnant or lactating; previous history of chronic corticosteroids, thyroid hormone or desmopressin use, physical signs suggestive of brain death or clinical death during the observation period. Laboratory data of 29 healthy volunteers, previously reported ${ }^{5}$ served as control.

Data collection - In the SBI patients, $10 \mathrm{~mL}$ blood samples were drawn on the $1^{\text {st }}\left(D_{1}\right), 2^{\text {nd }}\left(D_{2}\right), 3^{\text {rd }}\left(D_{3}\right)$ and $5^{\text {th }}$ day (D5) post-inclusion for measuring AVP and serum osmolality, using a previously placed venous catheter. A $3 \mathrm{~mL}$ arterial blood sample was also collected for gas analysis, electrolytes, hemoglobin, hematocrit, lactate and glucose, using a previously placed arterial catheter.

An isolated urinary sample at D1 and 24 hour urinary samples at $D_{2}, D_{3}$ and $D_{5}$ were used for sodium and osmolality measurements. Blood samples $(10 \mathrm{~mL})$ for measurement of urea, creatinine and for carrying out a leukocyte count were collected only once (at $D_{1}$ ). All samples were sent to specific laboratories for immediate evaluation, except the AVP sample. Blood gas analysis was carried out immediately following sampling in a Radiometer ABL 700 Series $^{\circledR}$.

At the time of blood sampling for AVP measurement, the following clinical parameters were recorded: systemic blood pressure (SBP), central venous pressure (CVP), heart rate, urinary output and body temperature.

AVP measurement was carried out at the Laboratory of Endocrine Physiology, Ribeirão Preto School of Medicine, University of São Paulo, as previously reported 5 .

During data collection, the volumes and types of fluid infused into the patients in the preceding 24 hours were registered for calculating the quantity of sodium that has been administered. Simultaneously, twenty-four hour urine collection was carried out, stored at $4^{\circ} \mathrm{C}$ and sent for measurement of urinary sodium. Sodium balance was then calculated at D2, D3 and D5.

Statistical analysis - For the purpose of statistical analysis the patients were divided into two groups: 1) patients with traumatic brain injury ( $\mathrm{TBl} ; \mathrm{n}=20$ ) and non-traumatic brain injury (NTBl; $n=16$ ); and 2) survivors (S) and non-survivors (NS). Some variables of interest were compared between groups at each time ( $D_{1} ; D_{2} ; D_{3}$ and $D_{5}$ after enrollment) as well as their respective evolutions in time within each group.

Samples' profile, according to the variables in the study, was carried out using frequency tables for categorical variables. Statistical analysis of continuous variables was described by using means, standard deviation and median. Categorical variables between groups were evaluated by using Chi-squared test or, when indicated, Fisher's exact test. To compare the basal characteristics between groups (NTBI and TBI), simple analysis of variance was used (oneway ANOVA). Multiple comparisons were performed using Tukey's post-hoc test. To analyze the relationship between numerical variables, Spearman's correlation coefficient was used. To study the relationship between variables of interest and the longitudinal levels of AVP, generalized estimation equations were used.

To analyze and compare the evolution of measured variables between two groups at the four times of sam- 
Table 1. Demographic and initial characteristics (D1) of patients with severe traumatic (TBI) and nontraumatic brain injury (NTBI).

\begin{tabular}{|c|c|c|c|}
\hline Characteristics & TBI $(n=19)$ & NTBI $(n=17)$ & $\mathrm{p}$-value \\
\hline Age (years) & $33(10)[31]$ & $41(15)[37]$ & 0.123 \\
\hline Sex (male/female) & $17 / 2$ & $14 / 3$ & $0.650 \mathrm{NS}$ \\
\hline Time from injury (hours) & $40(12)[38]$ & $36(15)[36]$ & 0.655 \\
\hline Admission GCS score & $5.4(2.0)[5]$ & $5.2(2.0)[6]$ & 0.604 \\
\hline Mean arterial pressure $(\mathrm{mmHg})$ & $98(14)[94]$ & $104(16)[104]$ & 0.091 \\
\hline Heart rate $(\mathrm{bpm})$ & $94(15)[95]$ & $86(22)[82]$ & 0.076 \\
\hline Central venous pressure $\left(\mathrm{cmH}_{2} \mathrm{O}\right)$ & $13(5)[12]$ & $11(4)[10]$ & 0.269 \\
\hline Axillary temperature $\left({ }^{\circ} \mathrm{C}\right)$ & $37.2(0.8)[37.4]$ & $36.9(0.8)[37.0]$ & 0.059 \\
\hline $\mathrm{PaO}_{2} / \mathrm{FiO}_{2}(\mathrm{mmHg})$ & $294(70)[312]$ & 278 (119) [267] & 0.623 \\
\hline Leukocyte count $\left(10^{3}\right.$.cells $\left./ \mathrm{mm}^{3}\right)$ & $13.3(7.1)[11]$ & $14.2(5.9)[12.9]$ & 0.311 \\
\hline Hematocrit (\%) & $29(6)[27]$ & $33(5)[32]$ & 0.472 \\
\hline Creatinine (mg\%) & $0.77(0.25)[0.75]$ & $0.86(0.33)[0.85]$ & 0.401 \\
\hline Serum sodium (mEq/L) & $141(8)[139]$ & $139(5)[138]$ & 0.867 \\
\hline Serum potassium (mEq/L) & $3.8(0.4)[3.7]$ & $3.7(0.7)[3.6]$ & 0.203 \\
\hline Glicemia (mg \%) & $140(29)[136]$ & $172(59)[153]$ & 0.067 \\
\hline Serum lactate (mMol/L) & $1.8(0.8)[1.5]$ & $2.3(1.2)[2.0]$ & 0.591 \\
\hline Serum osmolality (mOsm/L) & $300(16)[296]$ & $299(12)[296]$ & 0.696 \\
\hline Serum vasopressin (pg/mL) & $2.4(3.8)[1.3]$ & $2.2(1.4)[2.0]$ & 0.533 \\
\hline Urinary sodium (mEq/L) & $102(73)[80]$ & $107(78)[75]$ & 0.873 \\
\hline Urinary osmolality (mOsm/L) & $406(191)[380]$ & $483(248)[497]$ & 0.224 \\
\hline
\end{tabular}

Values are expressed as mean ( \pm standard deviation) [median]

pling, analysis of variance (ANOVA) for repeated measures was used. Comparisons between groups were made using Tukey's post-hoc test and comparison between times was made using the profile contrast test. Since there was no normal distribution, variables were transformed into ranks or posts. The Mann-Whitney test was used to compare values between groups.

Differences were considered significant if $p<0.05$.

\section{RESULTS}

Demographic and initial (D1) clinical and laboratory data from patients are shown in Table 1. No differences were found between them. AVP mean values of both groups were inside the normal range previously reported in normal volunteers ${ }^{5}$.

More neurosurgical procedures were carried out in NTBI than in TBI patients [15/17 (88\%) vs 8/19 (42\%), respectively; $p=0.006]$. The values of some variables of interest during observation time ( $D_{1}$ to $D_{5}$ ) in TBI and NTBI patients are shown in Table 2. Serum AVP levels remained inside the normal range, tending to decrease along the first week post-injury $(p=0.059)$, without differences between groups (Table 2). Additionally, in NTBI patients, sodium balance at D2 was more positive than that of $D_{3}(p=0.019)$, but no significant differences were found in comparison to TBI patients at any time.
Total in-hospital mortality of SBI patients was $42 \%$ (15/36 patients), and there was no significant difference in mortality between NTBI and TBI groups [8/17 (47\%) vs $7 / 19(41 \%)$, respectively; $p=0.535]$. Neurological related death was found in $9 / 15$ (6o\%) patients and occurred early (median 8,3 days post-injury) and non-neurological related death was found in 6/15 (40\%) patients (pneumonia/acute respiratory failure: 2 patients; ARDS: 1 patient; MODS: 2 patients and barotrauma: 1 patient) and occurred later (median 42 days post-injury).

Survivor and non-survivor patients were comparable in relation to age, initial GCS score and time from injury to inclusion in the protocol. These data and the values of some variables of interest during the observation period in survivor and non-survivor patients are shown in Table 3 . Its of note that larger fluctuations of serum sodium levels away from the normal range were more frequently seen in non-survivors than in survivors during the observation time $(p<0.001$ at D1, D2 e D4). These data are better appreciated in Figure 1. Serum osmolality variability was also higher in non-survivors than in non-survivors during the observation time $\left(p=0.009\right.$ at $D_{2}, D_{3}$ and $\left.\mathrm{D}_{5}\right)$. Oxygenation index $\left(\mathrm{PAO}_{2} / \mathrm{FiO}_{2}\right)$ has shown lower values in patients who died in relation to survi- 
Table 2. Evolution of some variables of interest during the observation period in patients with severe traumatic (TBI) and non-traumatic brain injury (NTBI).

\begin{tabular}{|c|c|}
\hline Variables & TBI $(n=19)$ \\
\hline \multicolumn{2}{|c|}{$\mathrm{PaO}_{2} / \mathrm{FiO}_{2}(\mathrm{mmHg})$} \\
\hline D1 & $294(70)[312]$ \\
\hline D2 & 299(75) [297] \\
\hline$D_{4}$ & $300(64)[297]$ \\
\hline$D_{5}$ & $266(108)[262]$ \\
\hline \multicolumn{2}{|c|}{ Serum sodium (mEq/L) } \\
\hline D1 & $141(8)[139]$ \\
\hline$D_{2}$ & $140(9)[137]$ \\
\hline$D_{3}$ & $141(10)[138]$ \\
\hline $\mathrm{D}_{5}$ & $140(9)[138]$ \\
\hline \multicolumn{2}{|c|}{ Glicemia (mg\%) } \\
\hline D1 & $140(29)[136]$ \\
\hline$D_{2}$ & $134(26)[129]$ \\
\hline$D_{3}$ & $143(40)[134]$ \\
\hline$D_{5}$ & $134(43)[125]$ \\
\hline
\end{tabular}

Serum lactate (mMol/L)

$\begin{array}{ll}\text { D1 } & 1.8(0.8)[1.5] \\ \text { D2 } & 1.7(0.6)[1.5] \\ \text { D3 } & 1.8(0.8)[1.7] \\ \text { D5 } & 2.3(1.7)[1.8]\end{array}$

Serum osmolality $(\mathrm{mOsm} / \mathrm{kg})$

D1 $300(16)[296]$

D2 298(19) [292]

D3 302 (20) [300]

D5 $299(20)$ [295]

Serum vasopressin $(\mathrm{pg} / \mathrm{mL})$

$\begin{array}{ll}\text { D1 } & 2.4(3.8)[1.3] \\ \text { D2 } & 1.6(0.9)[1.7] \\ \text { D3 } & 1.4(0.7)[1.4] \\ \text { D5 } & 1.9(2.0)[1.1]\end{array}$

Urinary sodium $(\mathrm{mEq} / \mathrm{L})$

$\begin{array}{lc}\text { D1 } & 102(73)[80] \\ \text { D2 } & 103(46)[105] \\ \text { D3 } & 116(44)[117] \\ \text { D5 } & 127(46)[123]\end{array}$

Urinary osmolality (mOsm/kg)

D1 $\quad 406$ (191) [380]

D2 $465(165)$ [400]

D3 437 (157) [432]

D5 397(135) [375]

Urinary volume $(\mathrm{mL} / 24 \mathrm{~h})$

$\begin{array}{ll}\text { D2 } & 5084(1694)[5550] \\ \text { D3 } & 4665(1782)[4580] \\ \text { D5 } & 5079(2744)[4150]\end{array}$

Sodium balance $(\mathrm{mEq} / 24 \mathrm{~h})^{(\mathrm{a})}$

\begin{tabular}{lll} 
D2 & $-182(288)[-215]$ & $75(457)[70]$ \\
D3 & $-20(341)[-80]$ & $-215(359)[-283]$ \\
D5 & $-125(296)[-151]$ & $-156(272)[-90]$ \\
\hline
\end{tabular}

Values are expressed as mean ( \pm standard deviation) [median]. ${ }^{(a)} \mathrm{D} 2 \neq$ D3 in NTBI.

139 (5) [138]

$143(9)[142]$

141 (9) [139]

$142(11)[137]$

0.867

172 (59) [153]

$148(41)[138]$

146 (33) [145]

0.067

$2.3(1.2)[2.0]$

$1.7(0.5)[1.6]$

$1.8(0.7)[1.6]$

$1.8(0.7)[1.7]$

299 (12) [296]

304 (20) [303]

301 (20) [298]

303 (24) [295]

$2.2(1.4)[2.0]$

$2.1(1.5)[1.5]$

$1.9(1.3)[1.5]$

0.591

0.696

107 (78) [75]

106 (86) [78]

127 (57) [134]

121 (73) [114]

0.224

482 (248) [497]

511 (246) [513]

485 (174) [511]

398 (152) [378]

5267 (3060) [4250]

5362 (3124) [4700]

4772 (2344) [3950]

0.893
Table 3. Demographic, basal characteristics and some variables of interest and their evolution during the observation period in survivor (S) and non-survivor (NS) patients.

\begin{tabular}{lccc}
\hline Variables & Survivors $(\mathrm{n}=21)$ & Non-survivors $(\mathrm{n}=15)$ & $\mathrm{p}$-value \\
\hline Age (years) & $38(15)[35]$ & $35(11)[33]$ & 0.772 \\
Sex (M/F) & $19 / 2$ & $12 / 3$ & 0.63 \\
Admission & $5.5(2.1)[6]$ & $5.1(2.0)[5]$ & 0.588 \\
$\begin{array}{l}\text { GCS score } \\
\text { Time from }\end{array}$ & $38(18)[36]$ & $38(18)[42]$ & 0.987 \\
injury (hours) & & &
\end{tabular}

144 (47) [130]

$1.3(0.9)[1.2]$

$\mathrm{PaO}_{2} / \mathrm{FiO}_{2}(\mathrm{mmHg})^{(\mathrm{a})}$

$\begin{array}{lc}\text { D1 } & 283(86)[295] \\ \text { D2 } & 309(83)[305] \\ \text { D3 } & 317(57)[315] \\ \text { D5 } & 348(120)[342]\end{array}$

291 (110) [335]

302 (88) [262]

$283(82)$ [290]

212 (68) [210]

Serum sodium (mEq/L)

$\begin{array}{lll}\text { D1 } & 140(5)[139] & 139(8)[136] \\ \text { D2 } & 139(6)[138] & 145(12)[146] \\ \text { D3 } & 140(8)[137] & 143(11)[142] \\ \text { D5 } & 139(6)[138] & 145(13)[146]\end{array}$

Glicemia (mg\%)

$165(47)$ [150]

138 (41) [129]

144 (31) $[134]$

$144(48)$ [130]

Serum lactate $(\mathrm{mMol} / \mathrm{L})^{(b)}$

$142(29)[136]$

146 (40) [142] 135 (42) [125]

2.0 (1.1) [1.6]

D2

$1.5(0.4)[1.5]$

$2.0(1.0)[1.9]$

1.9 (0.6) [1.9]

$2.1(0.9)[1.9]$

$2.6(1.8)[1.8]$$$
\text { D5 } \quad 1.7 \text { (0.5) [1.5] }
$$

Serum osmolarity $(\mathrm{mOsm} / \mathrm{L})^{(c)}$

$\begin{array}{lll}\text { D1 } & 300(13)[296] & 299(16)[296] \\ \text { D2 } & 296(14)[293] & 308(22)[316] \\ \text { D3 } & 298(18)[295] & 307(21)[303]\end{array}$

D5 $296(16)$ [292]

Serum vasopressin $(\mathrm{pg} / \mathrm{mL})^{(\mathrm{d})}$

$309(25)$ [314]

$\begin{array}{lcc}\text { D1 } & 2.2(3.6)[1.3] & 2.4(1.5)[2.5] \\ \text { D2 } & 1.6(1.2)[1.3] & 2.1(1.2)[2.0] \\ \text { D3 } & 1.4(1.2)[1.3] & 1.9(0.7)[1.9] \\ \text { D5 } & 1.1(0.8)[1.1] & 2.3(2.1)[1.4] \\ \text { Urinary sodium }(\mathrm{mEq} / \mathrm{L})^{(\mathrm{e})} & \\ \text { D1 } & 100(64)[75] & 110(89)[80] \\ \text { D2 } & 122(66)[105] & 80(63)[65] \\ \text { D3 } & 136(48)[143] & 101(48)[95] \\ \text { D5 } & 136(53)[136] & 107(65)[101]\end{array}$

Urinary osmolality ( $\mathrm{mOsm} / \mathrm{kg}$ )

$\begin{array}{lll}\text { D1 } & 506(201)[497] & 352(220)[294] \\ \text { D2 } & 472(203)[406] & 507(214)[513] \\ \text { D3 } & 455(142)[485] & 466(198)[491] \\ \text { D5 } & 418(118)[385] & 369(169)[310]\end{array}$

Urinary volume $(\mathrm{mL} / 24 \mathrm{~h})$

D2 4596 (1788) [4330] $5976(2942)$ [5700]

D3 $4413(1622)$ [4300] 5810 (3251) [4950]

D5 $4974(2354)[4900] \quad 4879(2846)$ [3850]

Sodium balance $(\mathrm{mEq} / 24 \mathrm{~h})^{(\mathrm{f})}$

$$
\begin{array}{llc}
\text { D2 } & -127(371)[-97] & 32(419)[26] \\
\text { D3 } & -122(312)[-125] & -99(426)[-51] \\
\text { D5 } & -232(286)[-279] & -10(223)[-27] \\
\hline
\end{array}
$$

Values are expressed as mean ( \pm standard deviation) [median]. ${ }^{(a)} \mathrm{S} \neq \mathrm{NS}$ at $D_{5} ; D_{5} \neq D_{1}$ in $N_{5}{ }^{(b)} S \neq N S$ at $D_{2}, D_{3}$ and $D_{5} ;{ }^{(c)} S \neq N S$ at $D_{2} ; D_{2} \neq D_{1}$ in $N S ;{ }^{(d)} S \neq N S$ at $D_{3} ;{ }^{(e)} S \neq N S$ at $D_{3} ;{ }^{(f)} S \neq N S$ at $D_{5}$. 

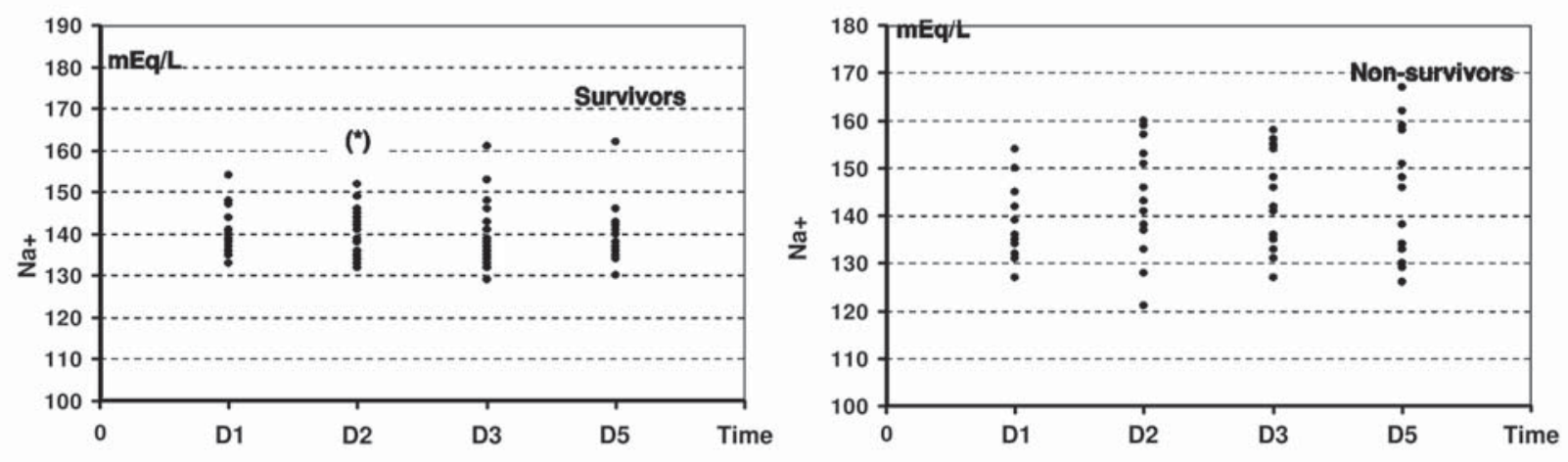

Fig 1. Fluctuations of serum sodium levels in survivors and non-survivors.

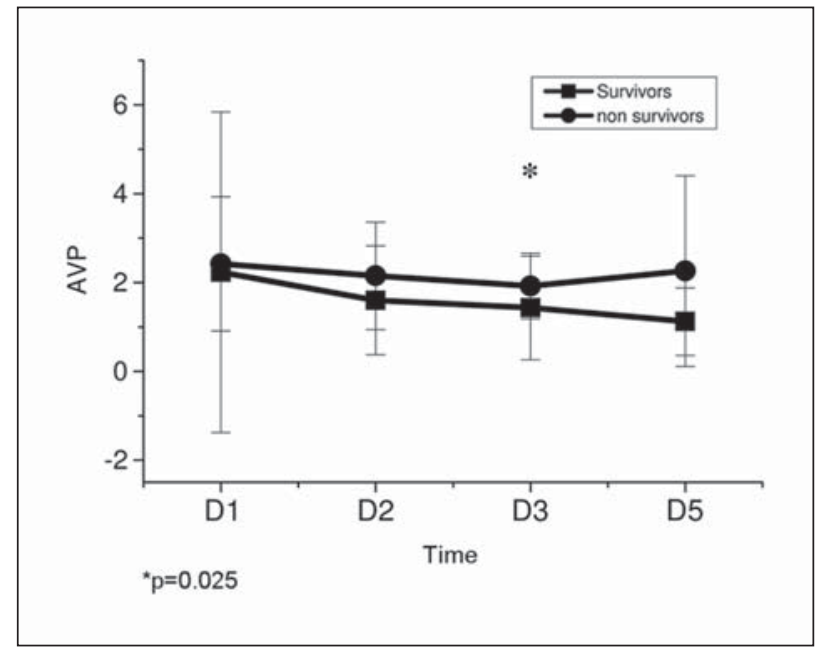

Fig 2. Vasopressin serum levels in survivors and non-survivors.

vors ( $p<0.001$ at $\left.D_{5}\right)$. Serum lactate was higher in patients who did not survive compared to survivors $(p=$ 0.029 at $D_{2}, D_{3}$ and $D_{5}$ ).

AVP serum levels, although ever remaining inside the normal range, were slightly higher in non-survivors than in survivors at $D_{3}(p=0.025)$. These data could be better appreciated in Figure 2 .

Severe hyponatremia (serum sodium $<120 \mathrm{mEq} / \mathrm{L}$ ) was not observed at any moment in this group of patients. Additionally, no significant correlation between AVP serum levels and serum sodium or serum osmolality could be demonstrated.

\section{DISCUSSION}

Plasma levels of AVP in healthy individuals at rest are usually very low. Chen et al. ${ }^{12}$ reported AVP levels ranging from 2.2-8.0 pg/mL in patients with normal volemia, normal blood pressure and serum osmolality $\leq 290 \mathrm{mOsm} / \mathrm{kg}$. In a study that evaluated endocrine failure following brain death, Gramm et al. ${ }^{13}$ used plasma AVP levels of $0.3-4.7 \mathrm{pg} / \mathrm{mL}$ as a reference value. Cintra et al. ${ }^{5}$ in normal resting adult individuals (control group), have reported plasma AVP levels of $2.22 \pm 1.15 \mathrm{pg} / \mathrm{mL}$, varying from $0.4-5.2 \mathrm{pg} / \mathrm{mL}$.

In the present study, mean AVP values in SBI patients were not significantly different from normal ranges. Similar findings had already been reported in a previous study carried out by the same authors, in which AVP serum levels in patients with SBI, despite of some individual variation expressed by plasmatic peaks, were comparable to those of the control group ${ }^{5}$. On the other hand, high serum AVP levels were found by Tenedieva et al. ${ }^{4}$ in patients with cerebral edema. These investigators reported that this alteration is related to the regulation of cardiovascular mechanisms and the development of cerebral edema. In a study to evaluate AVP levels in SBI, other investigators ${ }^{3}$ have suggested that the increase in intracranial pressure stimulates central vasopressin release.

Multiple endocrine abnormalities have been reported in patients with SBI, particularly secondary to stroke, and some of them play an important role in aggravating the neurological deficit. Various pathophysiological mechanisms have been proposed to explain these alterations, including the direct effect of neuronal death, vasospasm and cerebral edema. Apparently, AVP plays an important role in the pathogenesis of these alterations following a stroke ${ }^{8,14}$. However, the hypothesis that high AVP levels must be related to an increase in morbidity and mortality in patients with SBI couldn't be supported in our study. On the contrary, our data have shown that AVP serum levels always remained within the normal range in survivor and non-survivor patients.

Diabetes insipidus - Disorders of sodium and water balance are the most well-known complications in the acute phase of SBI, especially traumatic one, 
contributing towards an increase in early morbidity observed in these patients ${ }^{6}$. Many cases of DI in this acute phase are considered transitory, and permanent DI following TBI has been rarely reported ${ }^{15,16}$. Nevertheless, patients with a partial AVP deficit may be easily confounded, since symptoms are mild and the clinical course of the post-traumatic injury is frequently complicated by significant alterations in cognitive and neurological abilities ${ }^{16-19}$.

Post-traumatic DI may result from an inflammatory edema around the neurons of the hypothalamus or posterior pituitary that may recover following resolution of the swelling. This may also be a result of damage to the hypothalamic neurons in the supraoptic and paraventricular regions or in the terminal axons of the posterior pituitary. These abnormalities may be transient when the neurons make new connections or may be permanent if gliosis occurs ${ }^{15}$.

Little research has been carried out in the posterior pituitary function of survivors of TBI. Agha et al. ${ }^{16}$ reported a significant functional alteration in the gland, both in the early and later stages, suggesting that the treatment of these abnormalities is of vital importance in maximizing the potential for recuperation of these patients and reducing morbidity. Wong et al. ${ }^{20}$ reported the occurrence of DI in $3.7 \%$ of neurosurgical patients in an intensive care unit. In a retrospective study, Boughey et al. ${ }^{21}$ reported that the incidence of DI in patients with TBI was $2.9 \%$. However, these investigators excluded patients with incomplete data for diagnosis from the study, but failed to relate how many patients were excluded. Mean plasma sodium level in their study was $161 \mathrm{mEq} / \mathrm{L}$, suggesting that their patients were very critically ill ${ }^{21}$. Moreover, in this same study, moderate manifestations of DI were also confounded, since urine hypotonicity was defined at an arbitrary borderline value of 300 $\mathrm{mOsmol} / \mathrm{kg}$. In our study, serum sodium and plasma osmolality tended to be higher in non-survivor patients, confirming the observation that high plasma levels of sodium are strongly related to injury severity. However, in normal individuals, when plasma levels of sodium exceed $145 \mathrm{mEq} / \mathrm{L}$, there is an increase in AVP secretion, resulting in a maximum urinary concentration ${ }^{22}$. Therefore, urinary osmolality between 300-600 $\mathrm{mOsmol} / \mathrm{kg}$ in a hypernatremic patient may be inappropriately low and consistent with a diagnosis of $\mathrm{Dl}^{22}$.

The routine application of plasma AVP measurement in clinical practice, although feasible, has serious limitations due to the technical complexities involved, and the results must be interpreted with caution because its secretion is stimulated by stress, intracranial hypertension, pain, opioid drugs use, etc, factors that are frequently present in patients with severe neurological lesions ${ }^{10}$.

In the present study, AVP plasma levels tended to fall between D1 (0-72 hours post-injury) and D5 (72144 hours post-injury), although not statistically significant. Higher values were seen at D1, i.e., at the most acute phase of brain injury, the moment at which its liberation may be stimulated by stress and/or intracranial hypertension. The initially normal levels at $D_{1}$ and a subsequent fall in plasma AVP at D5 observed in this study point to the fact that these alterations have to be evaluated earlier (immediately following the causal event) and for a longer period following acute brain injury, as suggested by many authors ${ }^{16-19}$.

Syndrome of inappropriate antidiuretic hormone secretion - Studies on the prevalence of SIADH in post-TBI patients have resulted in conflicting data, with the incidence varying from $2.3 \%$ to $36.6 \%{ }^{10,23,24}$, reflecting different selection of diagnostic criteria for the patients studied. SIADH is caused by the uncontrolled release of AVP, resulting from damage to the posterior hypothalamic-pituitary axis ${ }^{10,23-25}$. Recognition and treatment of acute hyponatremia is of vital importance, since in hospitalized patients this disorder is associated with high morbidity and mortality $^{26}$. This is highly relevant in patients with SBI, since hyponatremia increases the risk of cerebral edema, which exacerbates the primary neurological injury and increases the risk of convulsions. In the present study, non-survivor patients have shown greater deviations from normal levels of serum sodium than the survivors, which is in agreement with findings in the literature that patients with significant alterations of serum sodium (hypo- or hypernatremia) may have more severe brain lesions and higher mortality rates ${ }^{27}$. However, none of our patients has shown severe hiponatremia or highly abnormal serum AVP levels during the observation time (five days), thus precluding the possibility of diagnosing SIADH.

In patients with intracranial hemorrhage and hyponatremia, high levels of AVP were reported in relation to a relative low plasma osmolality ${ }^{1}$. In other studies, AVP levels in patients with SAH decreased after remaining high for two days, and many of these patients did not develop hyponatremia until the end of the first week ${ }^{28}$. In a study carried out in 298 patients with $\mathrm{SAH}$, the patients developed both hypernatremia and hyponatremia; however, hypernatremia 
was associated with more severe brain lesions and higher mortality rates. Nevertheless, the investigators suggested that further studies should be carried out to determine the underlying mechanism present in this hypernatremia ${ }^{27}$.

Cerebral salt-wasting syndrome (CSWS) - Cerebral salt-wasting syndrome has been proposed as an alternative for explanation of hyponatremia in patients with intracranial disorders. In this syndrome, primary natriuresis leads to a negative sodium balance and reduction in extracellular volume. To correct the circulating volume, the regulators of plasma volume, i.e.: the renin-angiotensin-aldosterone system, the sympathetic nervous system and the AVP secretion, are activated. Indeed, despite hypo-osmolality, vasopressin secretion is not suppressed in patients with hyponatremia following intracranial bleeding or $\mathrm{SAH}^{1,8,28}$. This "inappropriate" AVP secretion is, in fact, appropriate with respect to the reduction in circulatory volume and, consequently, the regulation of volume prevails over osmoregulation. In practice, it is very important to determine the cause of hyponatremia in patients with intracranial disorders, and CSWS should be clearly differentiated from SIADH since their management principles are virtually opposites ${ }^{10}$.

However, the pathophysiology of CSWS is still controversial. Some authors have reported that increased atrial natriuretic peptide (ANP) may cause hyponatremia ${ }^{28-30}$. Sviri et al. ${ }^{30}$ reported that brain natriuretic peptide (BNP) levels increases shortly after head injury and remains continuously elevated during the acute phase in patients with extensive SAH and in those with high intracranial pressure (ICP), showing a positive correlation with poor outcomes.

The literature emphasizes the fact that the increase in the permeability of the cerebral capillaries is one of the most important mechanisms responsible for the maintenance of cerebral edema in patients with SBI and that the alterations in sodium and AVP may contribute greatly to the maintenance of this homeostasis ${ }^{16,24}$.

There is relevant evidence in the literature that sodium and water disturbances associated with SBI may aggravate primary brain lesion and lead to irreversible neuronal damage ${ }^{10,16,24}$. Nevertheless, much remains undefined with respect to the differentiation of the syndromes involving these disturbances, particularly between SIADH and CSWS. There is a consensus in the literature that investigations on this subject should seek to achieve early recognition of these alterations and subsequent prevention of the disturbances that may lead to deterioration of the brain lesion $6,10,16,24$.

In the present study, patients with severe brain lesions (traumatic or not) presenting greater serum sodium deviations from the normal range during the observation period have shown higher mortality rates.

Respiratory and metabolic disturbances - Acute neurogenic pulmonary edema, a common and underdiagnosed complication, can occur after virtually any form of injury to the central nervous system and is a potential early contributor to pulmonary dysfunction in patients with head injury. Bahloul et al. ${ }^{31}$ evaluated myocardial function in patients with evident neurogenic pulmonary edema after TBI, and found that every patient with neurogenic pulmonary edema also had myocardial dysfunction. The mechanisms responsible for myocardial dysfunction were multiple, and the investigators suggested that further studies are needed to adequately understand the pathophysiology of this pulmonary and cardiac dysfunction.

Wu et al. ${ }^{32}$ suggested that increased intracranial pressure secondary to brain hemorrhage may promote localized activation of cytokines and coagulation system, including tissue factors release. However, whether intracerebral hemorrhage triggers inflammation in noncerebral organs has not been elucidated.

In our patients, some degree of acute pulmonary dysfunction has been observed, expressed by a fall in $\mathrm{PaO}_{2} / \mathrm{FiO}_{2}$ relationship, but no overt pulmonary failure (either pulmonary edema or acute respiratory distress syndrome) has been recorded. A progressive deterioration of pulmonary function was seen in non-survivor from $D_{1}$ to $D_{5}$, but this could only be a reflex of a more severe brain lesion in these patients.

In SBI patients altered cell metabolism is described, and this fact has been attributed to neurohormonal abnormalities secondary to hypothalamic-hypophyseal dysfunction ${ }^{33}$. Recent experimental studies have demonstrated that some degree of brain mitochondrial dysfunction occurs early in acute traumatic brain injury and could play an important role in post-injury neuronal abnormalities ${ }^{34,35}$. Some investigators hypothesize that mitochondrial oxidative damage and dysfunction precede the onset of neuronal loss after controlled cortical impact traumatic brain injury, and suggest that future studies directed at reversing mitochondrial abnormalities could guide neuroprotective interventions after TBI35.

Increased anaerobic metabolism and acid-base and electrolyte abnormalities are frequently seen in severe brain injured patients the consequences of this 
derangement ${ }^{33}$. Indeed, in the present study, patients with severe brain lesions (traumatic or not), especially those who died, have shown increased serum lactate levels and great serum sodium deviations from the normal range during the observation period. So, it is important to emphasize the need for a strictly monitoring of hydroelectrolytic, acid-base and metabolic status during the evolution of SBI patients and attempting to clearly define the cause of these alterations, with the objective of proposing therapeutic measures to minimize the risk of aggravating the primary brain lesion and the morbidity-mortality rates.

In conclusion, there was a slight variability of serum AVP levels in patients with SBI, seen as isolated plasmatic peaks, but their mean values always remained within the normal range, and these levels tended to decrease over time, both in survivors and non-survivors. Serum sodium and plasma osmolality have shown great variations in patients with SBI, and non-survivors have shown greater and more significant deviations from normal values than those who survived. These data permit us to conclude that patients with SBI have relatively frequent and serious disorders of sodium and water balance during their evolution in the acute phase, and the greater these alterations, the greater the mortality rates. Nevertheless, these results do not allow us to make a clear differentiation between the different syndromes involved in sodium and water disturbances in patients with SBI, suggesting that they need to be studied at an earlier stage and for longer periods to enable better characterization and differentiation of these alterations, as well as to define more clearly whether these disturbances aggravate the primary brain lesion or if they are merely a reflex of injury severity.

\section{REFERENCES}

1. Kamoi K, Toyama M, Takagi M, et al. Osmoregulation of vasopressin secretion in patients with the syndrome of inappropriate antidiuresis associated with central nervous system disorders. Endocr J 1999; 46:269-277.

2. Mather HM, Ang V, Jenkins JS. Vasopressin in plasma and CSF of patients with subarachnoid hemorrhage. J Neurol Neurosurg Psychiatry 1981;44:216-219.

3. Sorensen PS, Gjerris F, Hammer M. Cerebrospinal fluid vasopressin and increased intracranial pressure. Ann Neurol 1984;15:435-440.

4. Tenedieva VD, Lyamin PV, Nepomnyaschi VP. The plasma and CSF vasopressin levels in brain tumors with brain edema. Acta Neurochir (Wien) 1994;60(Suppl):S387-S389.

5. Cintra E de A, Maciel JA Jr, Araújo S, et al. Vasopressin serum levels in patients with severe brain lesions and in brain-dead patients. Arq Neuropsiquiatr 2004;62:226-232.

6. Kaufman HH, Timberlake G, Voelker J, Pait TG. Medical complications of head injury. Med Clin N Am 1993;77:43-60.

7. Qu F, He X, Lu W, Wang Y. Neurohypophyseal AVP concentration in stroke patients. Chin Med J 1995;108:259-261.

8. Kurokawa $Y$, Uede T, Ishiguro M, et al. Pathogenesis of hyponatremia following subarachnoid hemorrhage due to ruptured cerebral aneurysm. Surg Neurol 1996;46:500-508.

9. Peters JP, Welt LG, Sims EA, Orloff J, Needham J. A salt-wasting syn- drome associated with cerebral disease. Trans Assoc Am Physicians 1950;63:57-64.

10. Bracco D, Favre JB, Ravussin P. Les hyponatremies en neuroréanimation: syndrome de perte de sel et secrétion inappropriée d'hormone antidiurétique. Ann Fr Anesth Réanim 2001;20:203-212.

11. Laszló FA, Varga C, Dóczi T. Cerebral oedema after subarachnoid haemorrhage. Pathogenetic significance of vasopressin. Acta Neurchir (Wien) 1995;133:122-133.

12. Chen JM, Cullinane S, Spanier TB, et al. Vasopressin deficiency and pressor hypersensitivity in hemodynamically unstable organ donors. Circulation 1999;100(Suppl):S244-S246.

13. Gramm HJ, Meinhold H, Bickel U, et al. Acute endocrine failure after brain death? Transplantation 1992;54:851-857.

14. Franceschini R, Tenconi GL, Zoppoli F, Barreca T. Endocrine abnormalities and outcome of ischaemic stroke. Biomed Pharmacother 2001; 55:458-465.

15. Yuan $X Q$, Wade CE. Neuroendocrine abnormalities in patients with traumatic brain injury. Front Neuroendocrinol 1991;12:209-230.

16. Agha A, Thornton E, O'Kelly P, Tormey W, Phillips J, Thompson CJ Posterior pituitary dysfunction after traumatic brain injury. J Clin Endocrinol Metab 2004;89:5987-5992.

17. Huang W, Yang Y, Wu S, Jin Z, Bao D, Gan H. Early changes of arginine vasopressin and angiotensin II in patients with acute cerebral injury. Chin J Traumatol 2001;4:161-163.

18. Yang Y, Huang W, Lu X. Early changes of endothelin, nitric oxide and arginine vasopressin in patients with acute cerebral injury. Chin J Traumatol 2002;5:259-262.

19. Chang Y, Chen TY, Chen CH, Crain BJ, Toung TJ, Bhardwaj A. Plasma arginine-vasopressin following experimental stroke: effect of osmotherapy. J Appl Physiol 2006;100:1445-1451.

20. Wong MF, Chin NM, Lew TW. Diabetes insipidus in neurosurgical patients. Ann Acad Med Singapore 1998;27:340-343.

21. Boughey JC, Yost MJ, Bynoe RP. Diabetes insipidus in the head-injured patient. Am Surg 2004;70:500-503.

22. Baylis PH, Thompson CJ. Diabetes insipidus and hyperosmolar syndromes. Becker KL (Ed). Principles and practice of endocrinology and metabolism, 3.Ed. Philadelphia; Lippincott, Williams \& Wilkins, 2001 285-293

23. Vingerhoets F, de Tribolet N. Hyponatremia hypo-osmolarity in neuro-

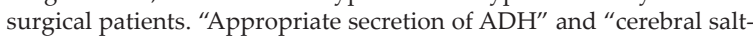
wasting syndrome". Acta Neurochir (Wien) 1988;91:50-54.

24. Coenraad MJ, Meinders AE, Taal JC, Bolk JH. Hyponatremia in intracranial disorders. Neth J Med 2001;58:123-127.

25. Sane T, Ranstakari K, Poranen A, Tahtela R, Valimaki M, Pelkonen R Hyponatremia after transsphenoidal surgery for pituitary tumors. J Clin Endocrinol Metab 1994;79:1395-1398.

26. Verbalis JG. Inappropriate antidiuresis and other hyposmolar states. Becker KL (Ed). Principles and practice of endocrinology and metabolism, 3.Ed. Philadelphia; Lippincott, Williams \& Wilkins, 2001:293-305.

27. Qureshi AI, Fareed MKS, Sung GY, Straw RN. Prognostic significance of hypernatremia and hyponatremia among patients with aneurismal subarachnoid hemorrhage. Neurosurgery 2002;50:749-755.

28. Isotani E, Suzuki R, Tomita K et al. Alterations in plasma concentrations of natriuretic peptides and antidiuretic hormone after subarachnoid hemorrhage. Stroke 1994;25:2198-2203.

29. Shimoda M, Yamada S, Yamamoto J, Tsugane R, Sato O. Atrial natriuretic polypeptide in patients with subarachnoid hemorrhage due aneurysmal rupture. Correlation to hyponatremia. Acta Neurochir (Wien) 1989;97:53-61.

30. Sviri GE, Soustiel JF, Zannroor M. Alteration in brain natriuretic atrial (BNP) plasma concentration following severe traumatic brain injury. Acta Neurochir (Wien) 2006;148:529-533.

31. Bahloul M, Chaari AN, Kallel H et al. Neurogenic pulmonary edema due to traumatic brain injury: evidence of cardiac dysfunction. Am J Crit Care 2006;15:462-470.

32. Wu S, Fang CX, Kim J, Ren J. Enhanced pulmonary inflammation following experimental intracerebral hemorrhage. Exp Neurol 2006;200:245-249.

33. Nygaard CE, Townsend RN, Diamond DL. Organ donor management and outcome: review from a level 1 trauma center. J Trauma 1990; 30:728-732.

34. Robertson CL, Saraswati M, Fiskum G. Mitochondrial dysfunction early after traumatic brain injury in immature rats. J Neurochem 2007; 101:1248-1257

35. Singh IN, Sullivan PG, Deng Y, Mbye LH, Hall ED. Time course of posttraumatic mitochondrial oxidative damage and dysfunction in a mouse model of focal traumatic brain injury: implications for neuroprotective therapy. J Cereb Blood Flow Metab 2006;26:1407-1418. 